\title{
Semiconductor Wafer Loss and Efficiency Improvement Using the Contradiction of TRIZ
}

\section{TRIZ의 모순을 이용한 반도체 웨이퍼 손실 및 효율개선}

\author{
Hong Kyun Shim ${ }^{1}$, Yong Won Song ${ }^{2}$, Joun Seon $\mathrm{Noh}^{3}$ \\ 심홍균 ${ }^{1}$, 송용원 ${ }^{2}$, 노준선 3 \\ ${ }^{1}$ Engineer, SK Hynix Semiconductor Co., Ltd., Korea, hongkyun.shim@sk.com \\ ${ }^{2}$ Professor, Dept. Nano \& Semiconductor Engineering, Korea Polytechnic University, Korea, \\ ywsong@kpu.ac.kr \\ ${ }^{3}$ Engineer, SK Hynix Semiconductor Co., Ltd., Korea, jounseon.noh@sk.com \\ Corresponding author: Yong Won Song
}

\begin{abstract}
With the growth of artificial intelligence and Big Data-related industries, the semiconductor industry, which is an essential element, continues to develop. Currently, semiconductors are being developed using nanometa-scale wire widths tens of thousands of times thinner than hair, and they are being applied to production equipment for mass production. This paper addresses the problem arising from the Ashing process, which eliminates photoresist and helps form linewidth of semiconductor internal circuits, among numerous processes that form circuits on wafers during the semiconductor manufacturing process. In the process of proceeding with the etching process, a wafer slides occurs inside a pressure conversion space called an air lock. Due to this problem, wafer loss occurs, and the operation of the device is stopped due to the stop of the production equipment, resulting in a problem of decreasing efficiency. Due to this problem, wafer loss occurs, and the operation of the device is stopped due to the stop of the production equipment, resulting in a problem of decreasing efficiency. Semiconductor production also decreases due to the decrease in efficiency of production equipment. Only by reducing chip losses and maximizing efficiency can limited equipment and maximum production without loss within a certain period of time can companies benefit. Semiconductor production is also reduced due to reduced efficiency of production equipment. Only when wafer loss is reduced and efficiency is maximized can limited equipment and maximum production without loss in a given time, which is linked to corporate profits. This paper is aimed to solve the problem of reducing chip loss and decreasing efficiency by improving the instantaneous maintenance (BM) of the device, which is one of the reasons for the decrease in efficiency of the device. Although two characteristics that contradict one physical property are required, the exact problem is solved by analyzing the cause and effect of TRIZ's problem solving method and chain analysis, and the contradiction problem is solved by using 40 inventive principles.
\end{abstract}

Keywords: CONTRADICTION, VESPEL, ETCH, TRIZ

요약: 인공지능과 Big Data 관련 산업이 성장함에 따라 필수적 요소인 반도체 산업은 발전을 거듭하고 있다. 현재의 반도체는 머리카락보다 수만 배 더 얇은 나노 미터 스케일 두께의 선폭을 이용하여 집적도가 높은 반도체가 개발되고 있으며, 이를 생산장비에 적용하여 대량

Received: June 12, 2021; $1^{\text {st }}$ Review Result: July 27, 2021; $2^{\text {nd }}$ Review Result: September 13, 2021 Accepted: October 31, 2021 
생산을 한다. 본 논문은 반도체 제조 과정 중 웨이퍼에 회로를 형성하는 수많은 공정 중에서 반도체 내부 회로의 선폭의 형성을 도와주는 감광액(Photoresist)을 제거하는 식각(Ashing) 공정에서 발생하는 문제를 다루고 있다. 식각공정을 진행하는 과정 중 에어락이라고 하는 압력 변환 공간 내부에서 웨이퍼의 미끄러짐이 발생한다. 이 문제로 인하여 웨이퍼 손실이 발생하며, 또한 생산장비의 멈춤으로 인해 장비 가동이 정지되며 효율 저하 문제가 발생한다. 생산 장비의 효율 저하로 인하여 반도체의 생산량 역시 감소한다. 웨이퍼 손실을 줄이고 효율이 극대화되어야만 한정된 장비와 정해진 시간 안에 손실 없는 최대의 생산이 가능하며, 이는 기업의 이익과 연결된다. 생산장비 효율 저하의 한 원인인 장비의 순간 정지 (Break Maintenance, $\mathrm{BM}$ ) 문제를 개선 함으로써 웨이퍼 손실을 줄이는 동시에 효율이 저하되는 문제를 해결하였다. 한가지의 물성에 상반되는 두 가지의 특성이 요구되는 난제이었으나, TRIZ의 문제 해결 방법 중 원인 결과 사슬분석을 통하여 정확한 문제를 분석하였으며, 모순 문제를 40가지 발명원리를 이용하여 해결하였다.

핵심어: 모순, 베스펠, 식각, 트리즈

\section{1. 서론}

현재 반도체 산업은 약 $0.05 \mathrm{~mm} \sim 0.1 \mathrm{~mm}$ 인 머리카락의 두께보다 수천 배 더 얇은 두께인 $50 \mathrm{~nm} \sim 20 \mathrm{~nm}$ 선폭을 이용하여 집적도가 높은 적층화 반도체 소자가 개발되고 있다[1]. 개발이 완료되면 이를 생산장비에 알맞게 적용하여 높은 집적도를 가진 고품질 반도체의 대량생산이 이루어진다. 이러한 반도체의 제조는 크게 웨이퍼(Wafer) 제조, 산화, 포토, 식각, 증착 및 이온 주입, 금속 배선, 웨이퍼 자동 선별 (Electrical Die Sorting), 패키징 (Packaging) 등 크게 8대 공정으로 나뉘며 세부적으로 몇백 가지의 공정을 거치면서 생산이 된다[2]. 식각공정 중 한 부분인 Ashing 공정이 완료된 웨이퍼의 운송과정 중 압력변환 공간인 에어락 내부에서 웨이퍼의 떨림으로 인한 미끄러짐 문제가 발생한다. 미끄러짐 문제가 발생하면 연속적인 공정 장비 내에서 순간 정지 (Break Maintenance, BM) 문제가 발생한다. 순간 정지가 발생하면 생산장비는 해결이 완료될 때까지 정지되고, 이로 인한 해당 장비의 효율은 저하된다. 한정된 장비와 정해진 시간 동안 생산장비 효율이 극대화되어야 기업의 이익이 증가하지만, 순간 정지 문제가 발생하여 생산 하락 및 기업이익의 감소를 초래한다. 본 논문에서는 순간 정지에서 많은 비중을 차지하고 있는 웨이퍼 미끄러짐 현상을 분석하고 문제 해결 아이디어를 창의적으로 도출하는 연구를 진행하였다.

\subsection{Ashing 공정}

식각 공정은 감광액(Photo register)[3]을 도포하는 포토공정이 진행 완료된 웨이퍼에 플라즈마(Plasma)를 이용해 산화막(Oxide Film)을 식각하는 공정이다. 식각이 진행된 곳은 공간이 발생되며, 이 공간에 전기적 신호의 송 수신이 가능한 금속 전극을 생성 및 보호하는 공정이 진행된다[4]. Ashing 공정은 식각공정의 한 공정으로 식각이후 남아있는 감광액을 제거하여 다음 노광 공정을 진행할 수 있도록 하는 공정이다[그림 1]. 감광액의 제거는 높은 온도에서 제거가 용이하기 때문에, $300^{\circ} \mathrm{C}$ 정도의 높은 온도에서 진행된다. 노광 -> 식각 -> Ashing 공정 진행을 반복함으로써, 전기적 신호의 송 수신이 가능한 금속 
전극을 적층화 하여 $3 \mathrm{D}$ 메모리를 생산하게 된다. 여러 진행 공정 중 본 논문에서는 한 장비에 두 가지 공정이 모두 진행이 되는 Lam Research 사의 KIYO 장비에 대한 문제 다루고자 한다.

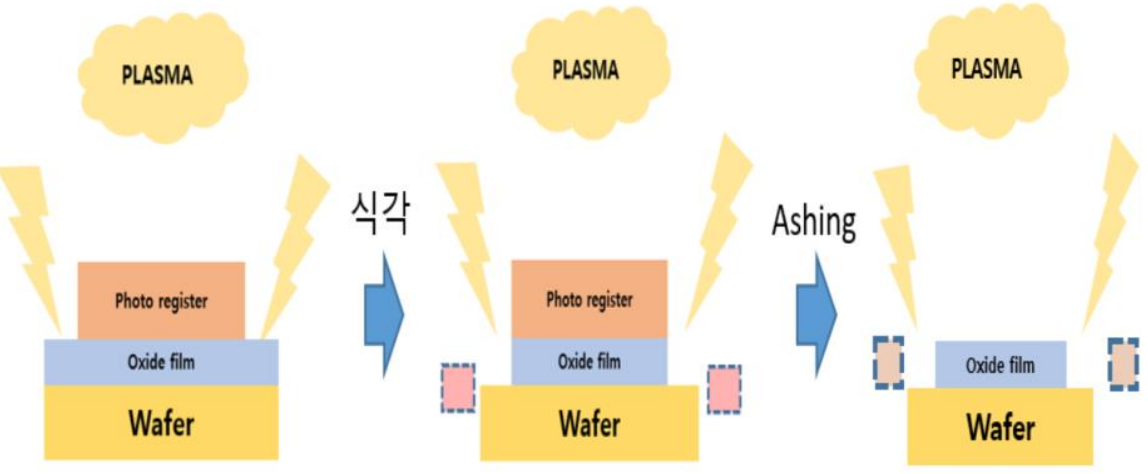

[그림 1] ETCH 공정

[Fig. 1] ETCH Process

\section{2 에어락}

반도체 제조를 진행하기 위해서는 진공상태에서 플라즈마를 이용하여 진행이 된다. 이로인해 웨이퍼는 대기압상태에서 진공으로 압력 변환이 이루어져야 한다. 에어락은 외부와 격리하여 압력 변환을 실시하는 공간이며, 이공간 안에서 공정 진행을 위한 웨이퍼는 대기압에서 진공으로 혹은 진행이 완료된 웨이퍼를 진공에서 대기압으로 압력이 변환된다. 에어락 내부는 2층으로 나누어져 웨이퍼가 놓이는 6 개의 받침대가 있으며 압력을 변환하기 위한 흡입 및 배출구, 압력 변환 시 외부와의 격리를 위한 진공 부 및 대기압부 Door 가 있다.

\subsection{TRIZ}

창의적 문제 해결 이론으로 알려진 트리즈(Theory of Inventive Problem Solving, TRIZ)는 러시아의 발명가 겐리히 알츠슐러(Genrich Altshuller)가 러시아 특허청에 등록된 약 20 만 건의 특허를 분석하여 수준에 따라 5단계로 나누고, 높은 3-5 수준의 문제를 어떻게 해결하였는지 분석하여 문제 해결의 공통 원리를 추출하여 만든 이론이다[5]. 특허 분석을 기반으로 발명된 트리즈의 문제 해결 방법 중 본 논문에서는 원인 결과 사슬 분석과 모순을 해결하는 40가지 발명원리를 활용하여 연구를 진행하였다.

\section{2. 문제 분석}

\section{1 문제 상황}

식각공정의 필수 요소인 플라즈마는 진공 상태에서 형성이 되며, 플라즈마 식각공정을 진행하기 위해 웨이퍼는 에어락이라는 압력 변화공간 대기압에서 진공으로 압력변환이 되어 이동하게 된다. Lam Research 사의 KIYO 장비는 플라즈마를 이용한 식각 및 Ashing을 한 장비의 독립된 $\mathrm{PM}$ (Process Module)에서 순차적으로 진행을 한다. 웨이퍼가 
진공 영역으로 운송된 후 식각 공정을 먼저 진행하게 되며, 진공 공간의 다른 $\mathrm{PM}$ 으로 운송되어 Ashing 공정을 진행한다. 식각 및 Ashing 공정 진행이 완료된 웨이퍼는 대기압으로 이동이 되어 공정 진행이 완료된다. 이때 웨이퍼의 이동은 로봇이 담당하며, 공정 진행을 위한 혹은 공정 진행이 완료된 웨이퍼의 압력 변환은 에어락이라는 공간이 담당한다. 에어락에서 압력이 변화되는 동안 웨이퍼는 받침대 위에 안착한 안정적인 상태로 압력 변화가 이루어져야 한다. 문제는 Ashing 공정이 완료된 이후 진공에서 대기압으로 압력 변환 중 웨이퍼의 안착 상태가 불량하여 웨이퍼의 떨림으로 인한 받침대에서 미끄러짐이 발생한다. 미끄러짐이 발생한 웨이퍼는 로봇의 움직임에 의한 간섭으로 흠집이 발생하거나 때로는 산산조각이 발생하는 손상이 발생하기도 한다[그림 3]. 또한 에어락에는 반입 반출 두 종류의 웨이퍼가 존재하는데 진행이 완료된 웨이퍼에서만 해당 문제가 발생하고 있다. 주 평균 6 건 발생이 되며, 이 중 1 건은 웨이퍼에 직접적인 피해가 발생한다. 이러한 문제가 발생하면 생산 중인 장비는 멈추게 되며, 순간 정지(Break Maintenance, BM)상태가 해결되어야만 생산이 재개된다. 이 문제는 생산성에 중대한 손실로 제품의 손실 및 생산의 손실까지 발생하는 중대한 문제이다. 시급한 해결이 필요한 문제이며, 근본 원인을 반드시 찾아서 제거해야 하는 문제이다. 본 논문에서는 에어락에서 발생하는 이문제를 해결하여 제품 손실 및 효율 하락 모두 해결하고자 한다.

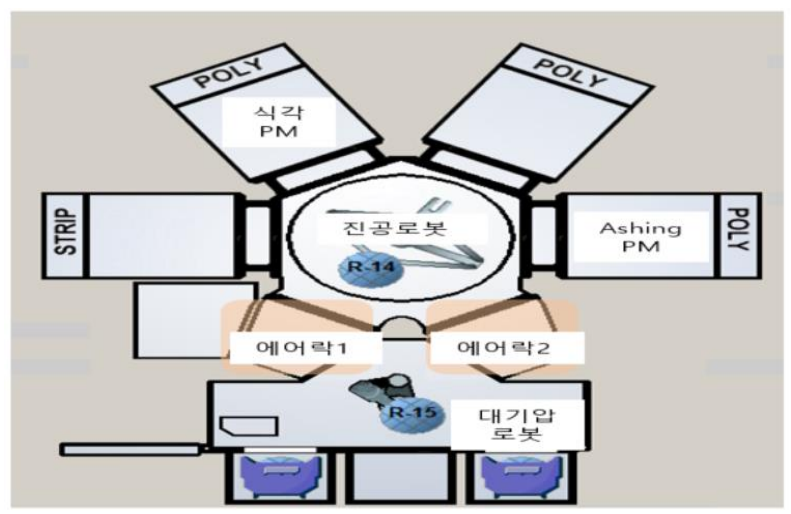

[그림 2] 장비 구성도

[Fig. 2] Equipment Configuration

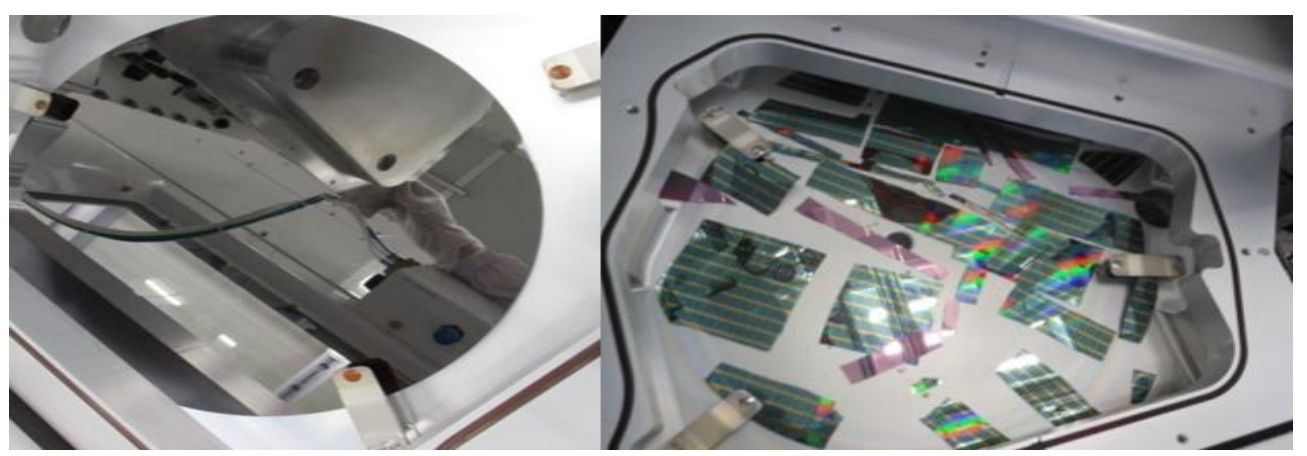

[그림 3] 문제 발생 상황

[Fig. 3] Problem Occurrence Situation 


\section{2 규제 및 제한조건}

웨이퍼의 미끄러짐 문제 해결에 있어 일정한 수준의 방법 및 재료의 변경은 필수적으로 필요하다. 그러나 제한 조건 및 변경이 불가능한 사항은 항상 있으며, 이를 지켜야 한다. 시스템에 포함된 내부와 외부 자원의 특성 및 공정 특성으로 인한 규제 및 제한 조건은 다음과 같다[표 1].

[표 1] 규제 및 제한조건

[Table 1] Regulations and Restrictions in Solving the Fume Retention Problem

\begin{tabular}{|c|l|}
\hline \multirow{4}{*}{ 제한 조건 } & (1) 로봇의 재질 및 운송방법 \\
\cline { 2 - 3 } & (2) 웨이퍼가 안착되는 받침대 위치 \\
\cline { 2 - 3 } & (3) 공정 진행 제조 방법(Recipe)의 변경 불가 \\
\hline \multirow{4}{*}{$\begin{array}{c}\text { 변경 가능 } \\
\text { 조건 }\end{array}$} & (1) 크기가 유지되는 상태에서의 변경 \\
\cline { 2 - 3 } & (3) 압력 변환할때의 소요시간의 진입 배출되는 Slot 위치 \\
\cline { 2 - 3 } & (4) 불순물의 영향이 없는 수준의 진공/대기압 변경 빠르기 \\
\hline
\end{tabular}

\section{3. 트리즈를 사용한 문제 분석}

\section{1 시스템 기능 분석}

\subsection{1 시스템 기능 분석}

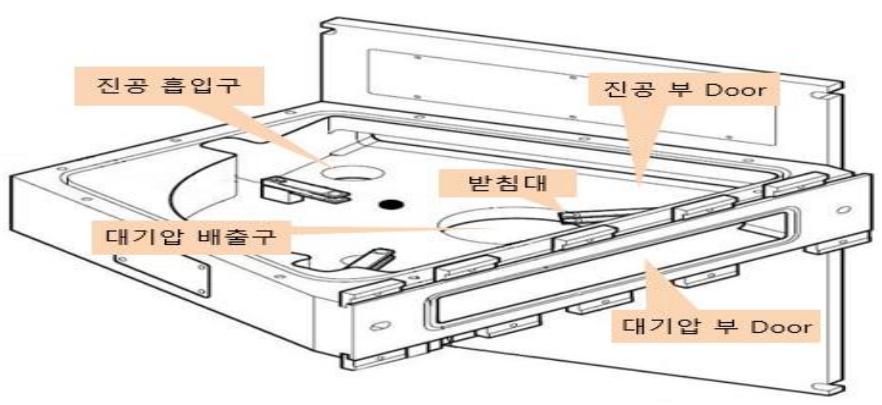

[그림 4] 에어락 도해

[Fig. 4] Airlock Illustration

\section{[표 2] 구성 요소 분석}

[Table 2] Component Analysis

\begin{tabular}{|c|c|}
\hline 받침대 & 압력 변환 시 웨이퍼가 위치하는 곳. 효율성을 위해 2층으로 되어 있음 \\
\hline 대기압 배출구 & 대기압으로 압력 변경 시 가스를 균일하게 공급하는 장치 \\
\hline 진공 흡입구 & 진공으로 압력 변경 시 에어락 내 기체 분자를 포집하는 장치 \\
\hline 진공 부 Door & 에어락과 진공부위를 격리 하기 위한 장치 \\
\hline 대기압 부 Door & 에어락과 대기압 부위를 격리하기 위한 장치 \\
\hline 진공 로봇 & 진공 부위에서 웨이퍼 운송을 담당하는 장치 \\
\hline
\end{tabular}




\begin{tabular}{|c|c|}
\hline Ashing 공정 & 식각 공정 진행 후 표면에 남은 감강액을 제거하기 위한 고온에서 진행되는 공정 \\
\hline 웨이퍼 & 반도체 제조의 기본이 되는 실리콘 재질의 원판 \\
\hline
\end{tabular}

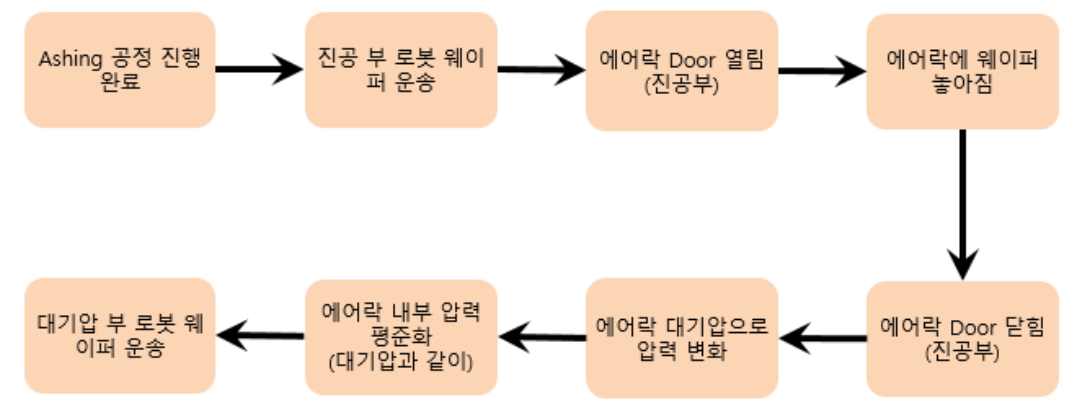

[그림 5] 프로세스 구성도

[Fig. 5] Process Diagram

\subsection{2 시스템 구성도 및 관계 파악}

어떠한 문제점으로 이러한 현상이 발생하는지 각 구성요소의 연관성을 확인할 수 있는 System 구성도[그림 5]를 이용한 분석을 하였다. 구성요소를 결합하여 각 부위에 영향을 가해주는지 받는지 어떠한 영향이 있을 수 있는지 화살표 방향으로 아주 간편하게 확인할 수 있는 트리즈 분석 기법이다. 정상적인 웨이퍼의 반입 반출이 이루어져야 하지만, 에어락으로의 반입은 정상이나, 반출에서 비정상인 상태를 가진다. 프로세스 구성도 및 시스템 구성도를 조합하여 문제를 분석해 보았다. 대기압부 로봇이 웨이퍼를 반출할 때 문제가 발생함으로 이 시점 이전에서 문제를 확인하도록 하였다. Ashing 공정은 고온의 상태에서 진행하게 되므로, 웨이퍼는 고온의 상태가 된다. 고온이라는 영향에 의해 문제가 발생할 수 있다. 고온의 웨이퍼는 식각량을 증가하여 생산량 증대에 필수적인 요건이다. 이후 진공 부 로봇이 웨이퍼를 운송한다. 로봇이 움직임에 따라 관성력이 영향을 미칠 수 있다. 웨이퍼는 에어락의 받침대에 안착하면 Door의 열리고 닫힘에 따라 진동이 발생한다. 대기압 배출구에서 Gas가 유입되어 압력변환이 될 때 역시 $\mathrm{Gas}$ 에 의한 진동이 발생한다. 열 / 진동 / 관성력 등의 영향이 웨이퍼에 전달이 된다.

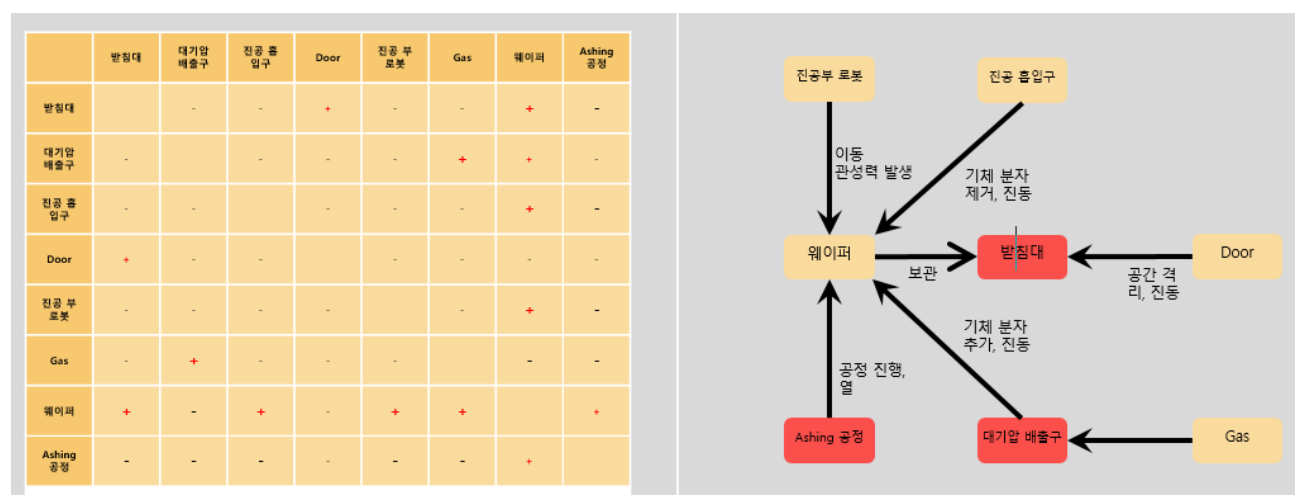

[그림 6] 기능도

[Fig. 6] Function Diagram 


\section{2 원인 분석}

문제 발생 시점은 대기압 부 로봇이 진행이 완료된 웨이퍼를 에어락에서 반출할 때 발생한다. 에어락은 장비에 2개가 있으며, 이 두 에어락 모두에서 발생한다. 이것으로 보아 Ashing 공정이 진행으로 인하여 문제가 발생함을 알 수 있다. Ashing 공정에서 사용하는 고온이 문제가 될 수 있다. 고온 진동을 확인해 보면, 고온의 물체가 차가운 물질과 접촉할 경우 진동이 발생한다. 이는 Warpage 현상[6][7]이라고 한다.

\subsection{1 원인 결과 사슬 분석(Cause-effect chain analysis : CECA) 분석}

문제가 발생하는 웨이퍼의 반출과정을 보다 면밀하게 살펴보기 위해 원인 결과 사슬 분석(Cause-effect chain analysis : CECA)분석을 실시하였다. 원인 결과 사슬 분석은 여러 가지 원인이 존재하는 문제를 Step by Step의 형태로 체계적으로 분석하는 방법이다. 원인과 결과 관계에 있어 유해한 작용이 발생하는 시간(Operation Time, OT)과 문제 발생 영역(Operation Zone, OZ)을 분석하여 문제 해결방법에 더욱더 쉽고 정확하게 도달 할 수 있다[8][9]. 웨이퍼는 에어락으로 반입되어 압력 변환이 완료되는 시점 안에 문제가 발생한다. 문제 발생 시점 안에 작용하는 영향은 시스템 구성도를 통하여 확인되었다. $\mathrm{CECA}$ 분석을 통하여 예상되는 문제 및 작용을 더 세밀하게 분석하였다. 에어락 받침대에서 웨이퍼의 미끄러짐 개선이 주목적으로 문제 발생 위치는 에어락 받침대 $(\mathrm{OZ})$ 이며, 문제 발생 시간은 웨이퍼가 에어락이 반입되어 에어락의 압력 변환이 완료될 때까지(OT) 이다.

웨이퍼는 진공 부 로봇에 의해 에어락으로 반입되며 받침대 안착 및 Door 닫힘, 에어락 압력변환 순서로 진행이 된다. 어떠한 상황에서도 웨이퍼는 에어락 받침대에 안정적으로 위치하여야 순간 정지 및 장비 생산성에도 안 좋은 영향이 발생하지 않는다. 그러나 고온의 웨이퍼는 안착 이후 Warpage 현상에 의한 진동이 기본적으로 발생한다. 이 진동과 함께 차가운 기체 분자 유입 및 Door 닫힘에 따른 압력 차에 역시 문제의 원인인 진동이 발생한다. 진동과 진동이 더해져 웨이퍼의 미끄러짐이 발생하는 것으로 확인되었다. 진동을 제어하여 웨이퍼를 안정된 상태로 유지하는 것에 대한 방법이 필요하였다.

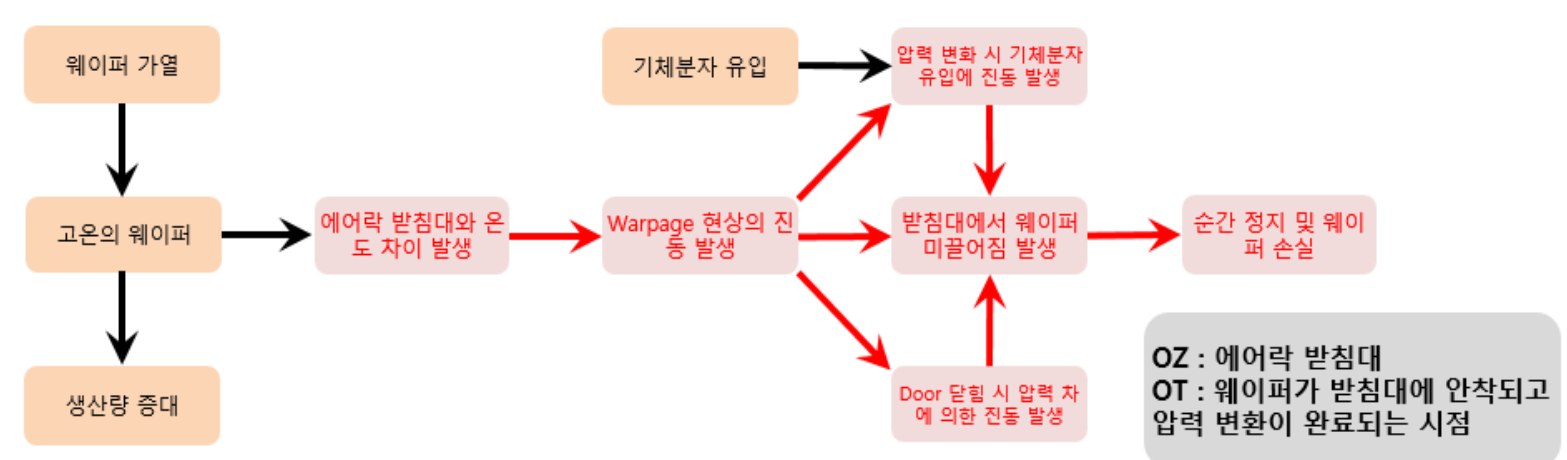

[그림 7] 원인 결과 사슬 분석

[Fig. 7] CECA Analysis 


\section{3 과제 정의}

문제를 분석을 통하여 원인을 규명하고, 문제의 해결을 위해서는 구체적인 과제를 결정해야 한다. 앞에서 진행한 문제분석을 통해 해결해야 할 문제를 “고온의 웨이퍼 안착 상태를 유지하여 미끄러짐을 방지하여 순간 정지 및 생산성 저하가 발생하지 않는 방법을 찾는 것'으로 과제를 정의하였다[그림 8].



[그림 8] 과제 정의

[Fig. 8] Task Definition

그동안 많은 방법으로 문제를 분석하였으며, 문제 해결 하고자 했었다. Door 닫힘의 진동을 제어하기 위해서 압력을 낮추었으나, 압력 변화 시 압력 불안정으로 인하여 실패하였다. 급격한 압력의 변화를 제어하기 위해 유입되는 $\mathrm{Gas}$ 의 압력을 변화하였으나, 압력변환 시간의 많은 소요로 인하여 생산량이 저하되었다. 열에 의한 진동의 문제는 Warpage 현상의 발생으로 발생을 한다. 그러나 문제를 제어하기 위한 효율적인 방법이 없었다. 문제를 제어하기 위해 트리즈의 창의적이고 강력한 문제 해결 방법이 필요하였다.

\section{4. 문제 해결}

\section{1 이상적 해결안 제시 (IFR: Ideal Final Result)}

이상적 최종 결과(IFR)는 기존 시스템의 장점은 그대로 유지하면서 단점은 제거한 이상적 해결안을 의미한다. 각각의 기법을 적용하여 이상적인 해결안을 탐색한다[10].

\subsection{1 기술적 모순의 발명 원리}

기술적 모순이란 하나의 시스템에서 한 가지 특성을 개선했을 때 다른 특성이 나빠지거나 새로운 문제가 발생하는 어려운 문제를 의미한다[11]. 현 상황의 기술적 모순은 Ashing 공정을 진행한 고온의 웨이퍼가 차가운 에어락의 받침대에 안착하였을 때 웨이퍼와 받침대 사이의 온도 차이로 인한 Warpage 현상이 발생하는 것이다. 만약 고온의 웨이퍼가 아닌 저온 상태로 에어락에 반입이 되면 Warpage 현상은 감소하지만, Ashing 공정 진행 후 고온의 웨이퍼를 차갑게 하는 공정이 증가하여 생산성은 저하된다. 
반면에 웨이퍼의 온도가 고온인 상태로 에어락에 반입이 되면 불필요한 공정이 없어져 생산성은 향상하나 Warpage 현상이 심화하여 안정성은 떨어진다. 그러나 생산성을 유지하는 것이 주목적이므로 고온의 웨이퍼 상태에서 개선 방안을 찾는 것이 필요하다.


[그림 9] 기술적 모순

[Fig. 9] Technical Contradiction

고온의 웨이퍼를 안정성 있게 하기 위하여 기술적 모순의 문제 해결 방법을 찾기 위해 발명원리를 적용하였다. 기술모순-2에서 좋아지는 특성은 '39.생산성'이며 나빠지는 특성은 '13.물체의 안정성'이다. 모순 행렬표(matrix)에 대입하였을 때 40가지 발명원리 중 ‘35-특성변환', ‘3-국부적성질', '22-해로운 것을 유익한 것으로 활용', '39-비활성 환경' 원리가 추천되었다. 고온의 웨이퍼는 변경이 불가능하므로 받침대와의 온도 차이를 최소화하여 Warpage를 최소화 할 수 있도록 아이디어를 도출하였다. 발명원리를 이용해 받침대의 접촉 부위를 열전달이 둔감한 물질로 변경한다. 받침대와 웨이퍼 사이에 물질을 삽입하여 열전달을 둔감하게 한다는 아이디어를 도출하였다.

[표 3] 발명 원리를 이용한 아이디어

[Table 3] Ideas Using Inventive Principles

\begin{tabular}{|c|c|c|}
\hline & $\begin{array}{l}\text { 악화되는 특성 } \\
\text { 13. 물체의 안정성 }\end{array}$ & 해결방법 \\
\hline \multirow{2}{*}{$\begin{array}{l}\text { 개선하려는 특성 } \\
39 . \text { 생산성 }\end{array}$} & 35. 특성 변환 & $\begin{array}{c}\text { 받침대의 접촉부위를 열전달이 둔감한 물질로 } \\
\text { 변경한다. }\end{array}$ \\
\hline & $\begin{array}{l}\text { 22. 해로운 것을 유익한 } \\
\text { 것으로 활용 }\end{array}$ & $\begin{array}{c}\text { 받침대와 웨이퍼 사이에 물질을 삽입하여 } \\
\text { 열전달을 둔감하게 한다. }\end{array}$ \\
\hline
\end{tabular}




\subsection{2 물리적 모순의 분리 원리}

기술적 모순 안에 있는 본질적인 물리적 모순을 분석하여 문제를 해결하고자 하였다. 물리적 모순은 문제가 발생하는 특정 요소에서 서로 다른 물리적 상태가 요구되는 것이다[11]. 물리적 모순은 시간 분리, 공간 분리, 부분과 전체 분리, 조건적 분리 원리를 이용하여 문제해결 아이디어를 도출한다. 본 연구에서 다루고 있는 문제의 물리적 모순은 공정 진행을 위해서는 웨이퍼는 고온이어야 하고, 미끄러짐이 없기 위해서는 저온이어야 한다는 것이다. 고온과 저온이라는 두 가지의 상태 모두를 충족해야 한다. 3 가지의 분리 원리를 이용하여 해결 아이디어를 도출하였다..

[표 4] 분리 원리를 이용한 아이디어

[Table 4] Ideas Using Separation Principles

\begin{tabular}{|c|c|}
\hline 분리 원리 & 해결 방법 \\
\hline 시간 분리 & $\begin{array}{c}\text { Ashing 공정시에만 고온을 유지하고, 에어락 반입시에는 저온이 가능 } \\
\text { 하도록 온도 하강 시간을 가진다. }\end{array}$ \\
\hline 공간 분리 & 에어락 반입 전에 온도 하강을 위한 공간을 마련한다. \\
\hline 부분과 전체 분리 & 진공 로봇을 저온으로 유지하여 운송시간동안 온도가 저하되도록 \\
한다.
\end{tabular}

\subsection{3 시스템 발전 법칙의 리듬 조화 법칙}

트리즈 이론 창시자인 알츠슐러는 기술시스템의 발전은 모순을 해결하면서 일정한 패턴에 따라 발전한다고 주장하였다. 이를 시스템 발전 법칙이라 한다. 이는 시스템의 탄생에서 성장하면서 더욱더 발전된 시스템으로 진화하는지 알 수 있다. 시스템 발전법칙 중 리듬 조화 법칙은 각각의 요소들의 형태나 주기 등 서로의 운동을 조화롭게 만들어 가면서 발전한다는 법칙이다. 고온의 웨이퍼와 저온의 받침대가 접촉되면서 일차적인 Warpage 현상으로 진동이 발생한다. 이후 기체 분자 유입, Door 닫힘에 따른 진동이 추가로 발생한다. 고온의 웨이퍼와 저온의 받침대 온도 차를 조화하기 위해 저온의 받침대에 열선을 장착하여 온도 차이를 최소화한다면, Warpage 현상을 제어 할 수 있다.

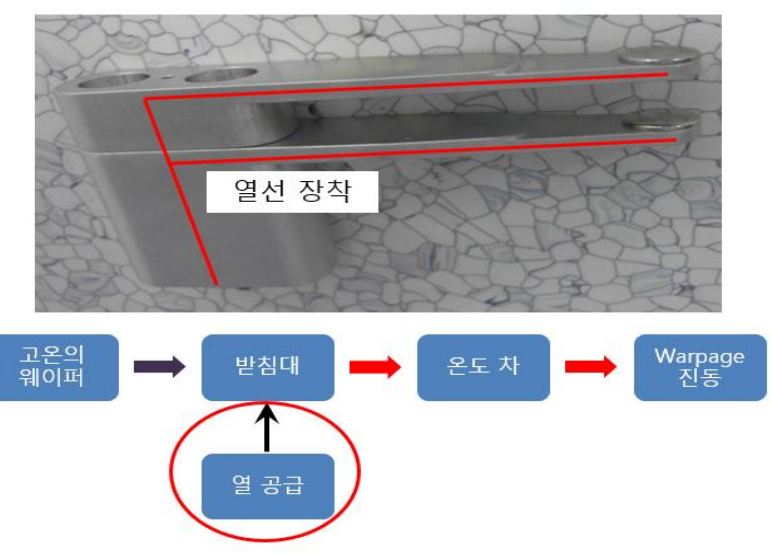

[그림 10] 시스템 발전 법칙

[Fig. 10] Law of System Development 


\subsection{4 물질 장 분석과 표준해}

트리즈 문제 해결 방식에는 복잡하고 어려운 대부분의 문제는 모순을 가지고 있으며, 이 기술적모순 및 물리적모순을 발명 원리와 분리 원리를 이용하여 창의적인 해결방법을 찾을 수 있다. 그러나 모순이 없거나, 쉽게 모순을 찾기 어려운 경우도 있다. 이러한 상황에서 사용하는 트리즈의 문제 해결 방법은 물질-장 분석을 실시하고 표준해를 이용하여 문제해결 방법을 찾는 것이다. 물질-장 분석은 두 물질과 그 사이에 작용하는 장(Field)을 분석하여 유익한 관계와 유해한 관계, 그리고 부족한 관계를 찾는 분석이다. 그리고 문제 형태에 따라 물질을 효과적으로 도입하여 해결안을 찾을 수 있는 체계적인 방법이다(표준해)[12]. 현재의 문제는 고온의 웨이퍼에서 발생하는 Warpage 현상으로 떨림이 발생하고 웨이퍼가 미끌어짐이 발생하는 것이다. 열전달을 둔감하게 하기 위해 열장 및 기계장을 투입할수 있다.



[그림 11] 물질 장 적용

[Fig. 11] Apply Su Field

[표 5] 물질 장을 이용한 아이디어

[Table 5] Ideas Using Su-field

\begin{tabular}{|c|c|}
\hline 물질 장 & 해결 방법 \\
\hline 열 & $\begin{array}{c}\text { 열전도를 최소화 하기 위해 흡열 반응이 최소화 되는 재질의 받침대 } \\
\text { 접촉부를 사용한다. }\end{array}$ \\
\hline 기계 & 웨이퍼와 접촉부를 크게하여 Warpage 현상을 둔화 한다. \\
\hline
\end{tabular}

표준해, 리듬 조화 법칙, 발명 원리를 활용하여 Warpage 현상의 둔화할 수 있는 새로운 물질의 도입과 온도 차를 최소화하기 위한 아이디어를 얻을 수 있었다.

\section{2 최종 해결안 도출}

도출된 아이디어를 종합하여, 최종 해결안 도출을 위한 평가를 진행하였다. 발명 원리, 표준해, 분리 원리, 리듬 조화 법칙을 이용하여 도출한 4 가지의 아이디어에 대한 평가를 진행하였다[그림 12]. 트리즈의 최종 해결안 평가는 이상성, 모순 해결, 현실성에 대해서 점수를 부여하여 합산 결과가 제일 높은 해결안을 채택한다. 평가 결과 경제적이고 적용 가능성이 가장 좋은 방법은 받침대 웨이퍼 접촉 부위 재질을 변경하는 것으로 채택이 되었다. 받침대를 확인하였을때, 웨이퍼와의 접촉 부위는 SUS 재질로 단독으로 탈착이 
가능하게 제작되어 있었다. 받침대 전체 변경이 아닌 특정 부분만의 변경 가능하여, 비용의 최소화 또한 가능하였다. 접촉 부위의 재질 변경으로 웨이퍼의 온도 전달이 둔화한다면 Warpage 현상도 둔화 할 수 있음으로, 근본 원인을 제거 할 수 있는 방법이다.

\begin{tabular}{|c|c|c|c|c|c|c|c|}
\hline \multirow{6}{*}{ 욤 } & \multirow{2}{*}{ No } & \multirow{2}{*}{ Idea 내용 } & \multicolumn{4}{|c|}{ Idea 평가( $\bigcirc: 5, \bigcirc: 3, \Delta: 1)$} & \multirow{2}{*}{ 순위 } \\
\hline & & & 이상성 & $\begin{array}{l}\text { 모순 } \\
\text { 해결 }\end{array}$ & 현실성 & 점수 & \\
\hline & 1 & 받침대의 웨이퍼 접촉 부위 재질 변경 & 0 & & 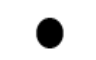 & 13 & 1 \\
\hline & 2 & 받침대 접촉 부 넓이 변경 & $\Delta$ & 0 & $\mathrm{O}$ & 7 & 3 \\
\hline & 3 & 받침대 열선 설치 & $\triangle$ & 0 & $\triangle$ & 5 & 4 \\
\hline & 4 & 온도 하향 시간 부여 & ? & 0 & $\triangle$ & 11 & 2 \\
\hline
\end{tabular}

[그림 12] 아이디어 평가표

[Fig. 12] Idea Evaluation Sheet

도입 가능한 물질을 확인 한 결과 신소재를 새로이 개발 개선을 하기보다, 이전에 장비에 도입이 되어 적용되어 사용중인 소재를 검토하였으며, 공정이 진행되는 Process Module 에서 사용중이며, 안정성이 검증된 Vespel 이라는 소재를 도입하였다. Vespel은 SUS304 보다 열전도율이 낮으며, 표면 거칠기가 거칠어 미끌어짐 현상을 제어하는데 효과적이라 판단되었다.

\begin{tabular}{|c|c|c|}
\hline & SUS 304 & VESPEL \\
\hline 열전도율 & $16.3 \mathrm{~W} / \mathrm{mK}$ & $0.35 \mathrm{~W} / \mathrm{mK}$ \\
\hline 표면 거칠기 & $0.64 \mu \mathrm{m} \leq \mathrm{Ra}$ & $1 \mu \mathrm{m} \leq \mathrm{Ra}$ \\
\hline
\end{tabular}


[그림 13] 받침대 재질 변경

[Fig. 13] Finger Material Change 
몇 차례의 변경을 통한 최종 해결안은 열전달을 최소화한 Vespel 재질의 받침대 접촉 부위와 Vespel 의 기계적 강도를 보강한 C Clip 고정 방식으로 채택하였다. 본 해결안으로 인하여 웨이퍼 손실은 주 평균 1 장에서 0 장으로 개선이 되었으며, 순간 정지 건수 주 평균 6건에서 0건으로 감소하여 효율 및 생산성이 개선되었다.



[그림 14] 최종 해결 안

[Fig. 14] Final Solution


[그림 15] 개선 효과

[Fig. 15] Improvement Effect

\section{5. 결론}

반도체 공정에서 발행하는 순간 정지 문제를 트리즈(TRIZ) 방법을 활용하여 개선하여 가동율이 향상되었다. 가동률 향상으로 생산성은 동반 상승하였으며, 웨이퍼 손실도 감소하면서 생산 이익도 증가하였다. 현재 Lam Research 전 장비에 본연구결과가 적용되어 순간 정지 감소에 많은 기여를 하고 있다. 본 사례를 통해 TRIZ 는 문제 분석 
단계에서부터 많은 분석 도구를 이용하여 정확히 분석하여, 다양한 창의적인 해결방법을 제시함으로써, 경제적이고 효율성이 제일 좋은 방안을 채택할 수 있도록 한다. 창의적인 문제 해결을 위한 트리즈 이론은 산업 현장에서 지식과 현실을 조합할 수 있는 최적화된 문제 해결 방법임이 입증되었다.

\section{6. 감사의 글}

This research was supported by Basic Science Research Program through the National Research Foundation of Korea (NRF) funded by the Ministry of Education (2018R1D1A1B07049244).

\section{References}

[1] D. Y. Kim, Latest semiconductor process technology, The Magazine of the IEIE, (2015), Vol 42, No.1, pp.91-98. Available from: https:/www.koreascience.or.kr/article/JAKO201508449473692.page

[2] http://www.samsungsemiconstory.com/2206, Jan 16 (2020)

[3] http://www.samsungsemiconstory.com/2523, Jan 06 (2021)

[4] http://www.samsungsemiconstory.com/1667, Jan 04 (2018)

[5] H. K. Shim, Y. W. Song, K. J. Lee, Utilization of TRIZ to Solve the Quality Problems in Semiconductor Etching Process, Asia-pacific Journal of Convergent Research Interchange, (2021), Vol.7, No.2, pp.99-109.

[6] B. W. Nam, J. G, Park, Investigation of Wafer Warpage Induced by Multi-layer Films, Journal of Semiconductor Technology and Science,(2018), Vol.18, pp.7-13.

[7] M. Wang, I. Hu, R. Y. C. Chen, C. Yeh, M. Shih, D. Tarng, Strip warpage assessment of dual side molding SiP module, IEEE 19th Electronics Packaging Technology Conference (EPTC), (2017), pp.1-5, DOI: 10.1109/EPTC.2017.8277508

[8] Y. W. Song, K. M. Kim, S. H. Kim, Creative Problem Solving Theory TRIZ, KSA Media, (2017)

[9] C. Dobrusskin, On the Identification of Contradictions Using Cause Effect Chain Analysis, Procedia CIRP, (2016), Vol.39, pp 221-224, DOI: 10.1016/j.procir.2016.01.192

[10] E. G. Kim, Inventive Problem Solving using IFR, Asia-pacific Journal of Multimedia Services Convergent with Art, Humanities, and Sociology, (2016), Vol.6, No.9, pp.473-481, DOI : 10.35873/ajmahs.2016.6.9.044

[11] J. S. Hyun, C. J. Park, Classification of Contradiction Relations and their Solving Dimensions based on the Butterfly Model for Contradiction Solving for Physical Contradiction of TRIZ, Knowledge Management Review, (2014), Vol.15, No.4, pp.15-34, DOI : 10.15813/kmr.2015.15.4.002

[12] H. K. Shim, Y. W. Song, K. J. Lee, Utilization if TRIZ to Solve the Quality Problems in Semiconductor Etching Process, Asia-pacific Journal of Convergent Research interchange, (2021), Vol.7, No.2, pp.99-109. 